\title{
Small-molecule COH-SR4 inhibits adipocyte differentiation via AMPK activation
}

\author{
JAMES L. FIGAROLA and SAMUEL RAHBAR

\begin{abstract}
Division of Diabetes, Endocrinology and Metabolism, Beckman Research Institute,
\end{abstract} \\ City of Hope National Medical Center, Duarte, CA 91010, USA
}

Received January 2, 2013; Accepted February 18, 2013

DOI: $10.3892 / \mathrm{ijmm} .2013 .1313$

\begin{abstract}
Obesity is a chronic metabolic disorder caused by an imbalance between energy intake and expenditure. It is one of the principal causative factors involved in the development of metabolic syndrome and cancer. Inhibition of adipocyte differentiation has often been a target of anti-obesity strategies since obesity is caused not only by hypertrophy but also by adipocyte hyperplasia. In this study, we investigated the effects of $\mathrm{COH}-\mathrm{SR} 4$, a novel compound with anticancer properties, on the adipogenesis in 3T3-L1 cells. Treatment with COH-SR4 significantly inhibited adipocyte differentiation in a dose-dependent manner. This inhibitory effect mainly occurred at the early phase of differentiation through inhibition of mitotic clonal expansion and cell cycle arrest at the G1/S phase transition. In differentiating adipocytes, COH-SR4 significantly reduced intracellular lipid accumulation and downregulated the expression of key adipogenesis-related transcription factors and lipogenic proteins. $\mathrm{COH}-\mathrm{SR} 4$ exhibited no cytotoxic effects in 3T3-L1 cells, but indirectly activated AMP-activated protein kinase (AMPK). AMPK activation by $\mathrm{COH}-\mathrm{SR} 4$ also resulted in the phosphorylation of raptor and tuberous sclerosis protein 2 (TSC2), two proteins involved in the mammalian target of rapamycin (mTOR) signaling pathways. Additionally, COH-SR4 decreased the phosphorylation of p70 kDa ribosomal protein S6 kinase (S6K) and initiation factor 4E (eIF4E) binding protein 1 (4EB-P1), two downstream effectors of mTOR that regulate protein synthesis. Interestingly, knockdown of AMPK $\alpha 1 / \alpha 2$ prevented the ability of COH-SR4 to inhibit cell cycle arrest and overall adipogenesis and lipid accumulation in the differentiating 3T3-L1 cells. Taken together, these results suggest that $\mathrm{COH}-\mathrm{SR} 4$ inhibits 3T3-L1 adipogenesis via AMPK activation. $\mathrm{COH}-\mathrm{SR} 4$ may be a promising compound for the treatment of obesity and related metabolic disorders.
\end{abstract}

Correspondence to: Dr James L. Figarola, Division of Diabetes, Endocrinology and Metabolism, Beckman Research Institute, City of Hope National Medical Center, Duarte, CA 91010, USA

E-mail: jfigarola@coh.org

Key words: AMPK, cell cycle arrest, 3T3-L1 adipocytes, COH-SR4, obesity, mTOR

\section{Introduction}

Obesity is a common metabolic disorder that is rapidly becoming a global public health problem. It is associated with an increased risk of several life-threatening diseases such as type 2 diabetes, cardiovascular diseases, and multiple types of cancer and may represent a leading preventable cause of death $(1,2)$. Obesity is characterized by pathologic growth of adipose tissues to accommodate excess energy intake through an increase in adipocyte number as a result of increased proliferation and differentiation (hyperplasia) and adipocyte size (hypertrophy) (3). Thus, targeting adipocyte biology via inhibition of adipocyte differentiation (adipogenesis) from fibroblastic preadipocytes into mature adipocytes and induction of apoptosis in adipose tissues, as well as identifying potential factors that regulate these processes are of great importance in the prevention and treatment of obesity (4).

The 3T3-L1 cell line is a well-established and widely used in vitro model of obesity for studying adipocyte differentiation. The differentiation process follows a precise ordered and temporal series of events regulated by a number of transcription factors and multiple signaling pathways for the development of the adipocyte phenotype $(5,6)$. The hormonal cocktail consisting of insulin, dexamethasone, and 3-isobutyl1-methylxanthine, activates an adipogenic program, which occurs in well-defined phases. The stimulated cells immediately re-enter the cell cycle and progress through at least two cell-cycle divisions, a phase often referred to as mitotic clonal expansion (MCE), a process essential for adipocyte differentiation (7). After MCE, the cells permanently withdraw from the cell cycle, begin to accumulate lipid, and undergo terminal differentiation into mature adipocytes. Induction of adipogenesis by hormones leads to the expression of specific adipogenic transcription factors CCAAT/enhancer binding proteins (C/EBPs), such as C/EBP $\beta, \mathrm{C} / \mathrm{EBP}$, adipocyte determination and differentiation-dependent factor $1 /$ sterol regulatory element-binding protein (ADD1/SREBP1), as well as cell cycle regulators that together facilitate expression and activity of peroxisome proliferator-activated receptor- $\gamma(\operatorname{PPAR} \gamma)$ and $\mathrm{C} / \mathrm{EBP} \alpha(5,6,8,9) . \mathrm{C} / \mathrm{EBP} \alpha$ and PPAR $\gamma$ then coordinately drive expression of adipocyte-specific genes such as adipocyte fatty acid-binding protein 2 (aP2), fatty acid synthase (FAS), acetyl-CoA carboxylase (ACC), lipoprotein lipase (LPL) and ATP citrate lyase (ACL) and cluster of differentiation (CD) 36, 
many of which characterize the final stages of differentiation $(5,6,8,9)$.

5'-AMP-activated protein kinase (AMPK) is a major regulator of cellular energy homeostasis which coordinates metabolic pathways in order to balance nutrient supply with energy demand. AMPK is activated by a variety of cellular stresses that decrease ATP generation including metabolic poisons as well as pathologic cues such as nutrient starvation, ischemia and hypoxia (10-12). Under these conditions, the activated AMPK phosphorylates many substrates that turn on alternative catabolic pathways to generate more ATP. Overall, AMPK activation leads to energy preservation for cell survival at the expense of growth and proliferation via long term transcriptional control of key players of various metabolic pathways. Interestingly, knockout of AMPK $\alpha 1$ or AMPK $\alpha 2$ subunits led to the development of obesity and insulin resistance in mice $(13,14)$. In addition, AMPK was proposed to be involved in the process of adipocyte differentiation, although its role in adipogenesis is not entirely understood. Several AMPK-activating compounds were found to have anti-adipogenic effects via MCE inhibition and downregulation of the adipogenic transcriptional pathways (15-18). Since AMPK is involved in the regulation of a variety of metabolic processes and plays a key role in glucose and lipid homeostasis, it is a promising target of anti-obesity agents.

Recently, our laboratory has identified several novel small-molecule compounds with anticancer properties. The lead compound COH-SR4 (Fig. 1A) showed potent antiproliferative activities against leukemia, melanoma, breast and lung cancers both in vitro and in vivo (19,20, unpublished data). Since cancer and obesity share several key metabolic regulators, we hypothesized that $\mathrm{COH}-\mathrm{SR} 4$ would also exhibit anti-adipogenic properties. In this study, we investigated whether $\mathrm{COH}-\mathrm{SR} 4$ prevents adipocyte differentiation, and examined its inhibitory mechanisms on 3T3-L1 adipogenesis, specifically AMPK activation, and associated downstream pathways.

\section{Materials and methods}

Chemicals, antibodies and reagents. COH-SR4 was synthesized according to a previously validated protocol by Dr Christopher Lincoln at the Chemical GMP Synthesis Facility, Translational Medicinal Chemistry Laboratory, Beckman Research Institute of the City of Hope (20). The purity of the compound was confirmed by ${ }^{1} \mathrm{H}-\mathrm{NMR},{ }^{13} \mathrm{C}-\mathrm{NMR}$ and HRMS-ESI analyses. COH-SR4 was dissolved in DMSO at $25 \mathrm{mM}$ stock solution. Antibodies against CDK2, cyclin E1, p27 ${ }^{\mathrm{Kip} 1}$, FAS, ACL, aP2, PPAR $\gamma$, AMPK $\alpha$, phospho-AMPK $\alpha$ (T172), ACC, phospho-ACC (S79), raptor, phospho-raptor (S792), TCS2, phospho-TSC2 (S1387), phospho-Akt (S473), Akt, S6K1, phospho-S6K1 (T389), phospho-4E-BP1 (S65) and 4E-BP were obtained from Cell Signaling Technology (Danvers, MA, USA). C/EBP $\alpha$ (p42) and SREBP1 antibodies were from EMD Millipore (Billerica, MA, USA), while S6K was obtained Santa Cruz Biotechnology, Inc. (Santa Cruz, CA, USA). The AdipoRed ${ }^{\mathrm{TM}}$ Adipogenesis Assay, XTT Proliferation Assay, CycLex AMPK Kinase Assay, and the colorimetric LDH Cytotoxicity Assay Kits were purchased from Lonza (Walkersville, MD, USA), American Type Culture
Collection (ATCC, Manassas, VA, USA), CycLex Co., Ltd., (Nagano, Japan), and BioVision (Milpitas, CA, USA), respectively. The recombinant active human AMPK $(\alpha 1 \beta 1 \gamma 1)$ was from SignalChem (Richmond, BC, Canada). AMPK $\alpha 1$, AMPK $\alpha 2$ and control siRNA were obtained from Invitrogen (San Diego, CA, USA) and Santa Cruz Biotechnology, Inc. All other chemicals and reagents were purchased from SigmaAldrich (St. Louis, MO, USA).

Cell culture and adipocyte differentiation. 3T3-L1 preadipocytes were obtained from Zen-Bio, Inc. (Research Triangle Park, NC, USA) and were cultured in Dulbecco's modified Eagle's medium (DMEM) containing 10\% (v/v) fetal bovine serum (FBS) (ATCC) and antibiotics at $37^{\circ} \mathrm{C}$ in a humidified atmosphere of $5 \% \mathrm{CO}_{2}$. Cells were subcultured every 2-3 days at $\sim 80-90 \%$ confluency. Depending on experiments, 3T3-L1 preadipocytes were plated in 6-, 12-, 24- or 48-well culture plates with the culture medium at a density that allowed them to reach confluence in 2 days. Two days after confluency (day 0), growth-arrested 3T3-L1 preadipocytes were incubated in differentiation medium (DM) cocktail containing $10 \mu \mathrm{g} / \mathrm{ml}$ insulin, $1 \mathrm{mM}$ dexamethasone and $0.5 \mathrm{mM}$ isobutylmethylxanthine together with or without $\mathrm{COH}-\mathrm{SR} 4$. On day 2, the medium was replaced with DMEM containing $10 \mu \mathrm{g} / \mathrm{ml}$ insulin only. Cells were then cultured in normal medium from day 4 to 7 . $\mathrm{COH}-\mathrm{SR} 4$ was added in every replacement of the medium except on experiments where it was added only on days $0-2,2-4$ or 4-7. On day 7, fully differentiated cells were harvested for protein analysis or stained with Oil Red O dye or AdipoRed reagent.

Oil Red $O$ staining. Cells on day 7 were washed twice with PBS, fixed with $10 \%$ neutral buffered formalin for $1 \mathrm{~h}$ at room temperature, washed with PBS and then dried completely. The fixed cells were stained with Oil Red O in an isopropanol/distilled water (6:4) solution for $30 \mathrm{~min}$ at room temperature and then washed twice with distilled water. The stained lipid droplets were observed, and microscopic images were obtained from randomly selected fields under a phase contrast microscope (AX70; Olympus, Tokyo, Japan) equipped with a digital camera and processed using ImagePro Plus software (Media Cybernetics, Silver Spring, MD, USA).

Triglyceride assay. Quantification of intracellular triglyceride content was measured on day 7 using a commercially available kit (AdipoRed Assay Reagent; Lonza) according to the manufacturer's directions. Fluorescence was measured with an excitation wavelength of $485 \mathrm{~nm}$ and emission wavelength of $572 \mathrm{~nm}$.

AMPK activity assay. AMPK activity was determined using the CycLex AMPK Kinase Assay kit according to the manufacturer's instructions. Briefly, recombinant active human AMPK $(\alpha 1 \beta 1 \gamma 1)$ was incubated with the indicated concentrations of AMP or COH-SR4 for $30 \mathrm{~min}$ at $30^{\circ} \mathrm{C}$ in a pre-coated plate with a substrate peptide corresponding to mouse insulin receptor substrate-1 (IRS-1). AMPK activity was measured by monitoring the phosphorylation of Ser-789 in IRS-1 using an anti-mouse phospho-Ser-789 IRS-1 monoclonal antibody and peroxidase-coupled anti-mouse IgG antibody. Conversion of 
the chromogenic substrate tetramethylbenzidine was quantified by absorbance measurement at $450 \mathrm{~nm}$.

Cell proliferation assay. Cell proliferation was determined using 2,3-bis-(2-methoxy-4-nitro-5-sulfophenyl)-2H-tetrazolium-5-carboxanilide (XTT) assay according to the manufacturer's instructions (ATCC). Briefly, cells were seeded on 48-well plates and incubated with test compounds for the indicated time periods. Activated XTT solution was then added to each well of the plate. After a 4-h incubation at $37^{\circ} \mathrm{C}$, the absorbance was measured at $475 \mathrm{~nm}$ using a reference wavelength of $630 \mathrm{~nm}$. In addition to the XTT assay, cell numbers were also estimated. Confluent 3T3-L1 preadipocytes were grown in 6-well culture plate and incubated with either DMSO vehicle or COH-SR4 (1-5 $\mu \mathrm{M})$ in DM cocktail medium for 1-2 days. The cells were trypsinized, harvested and counted using a cell counter (Z1 Coulter Counter; Beckman Coulter, Inc., Brea, CA, USA).

Cytotoxicity assay. 3T3-L1 preadipocytes were grown in a 48-well culture plate in DMEM with $10 \%$ FBS and antibiotics and incubated with either DMSO vehicle or COH-SR4 (1-5 $\mu \mathrm{M})$. After $48 \mathrm{~h}$, the released lactate dehydrogenase (LDH) into the culture supernatant was measured by the colorimetric LDH Cytotoxicity Assay (BioVision) according to the manufacturer's instructions.

Hoechst 33258 staining. After experimental treatment, cell cultures were fixed with $4 \%$ paraformaldehyde, washed twice with PBS, and stained with Hoechst $33258(5 \mu \mathrm{g} / \mathrm{ml})$ for $5 \mathrm{~min}$ in the dark, then followed by extensive PBS washes. Nuclear staining was examined under a fluorescence microscope and images were captured using ImagePro Plus software. Cells that exhibited reduced nuclear size, chromatin condensation, intense fluorescence, and nuclear fragmentation were considered as apoptotic.

Nucleotide extraction and measurement. Cellular levels of AMP, ATP and ADP were measured by UV-HPLC. In brief, 3T3-L1 preadipocytes were treated with $\mathrm{COH}-\mathrm{SR} 4$ for $60 \mathrm{~min}$. After the incubation period, cells were washed once with ice cold PBS, centrifuged, and $50 \mu 1$ of PBS and $50 \mu 1$ of $6 \%$ TCA was added to the cell pellet. After thorough mixing, the sample was placed in a $4^{\circ}$ sonicator for $10 \mathrm{~min}$ and then centrifuged at $14,000 \mathrm{rpm}$ for $10 \mathrm{~min}$. A $100 \mu \mathrm{l}$ aliquot of supernatant was removed and mixed with $100 \mu \mathrm{l}$ of deionized water. Finally, $18.5 \mu \mathrm{l}$ of $1 \mathrm{M} \mathrm{KOH}, 30 \mu \mathrm{l}$ of $150 \mathrm{mM} \mathrm{KH} \mathrm{PO}_{4} / 150 \mathrm{mM}$ $\mathrm{KCl}$ solution ( $\mathrm{pH} 6.0$ ) and $0.5 \%$ acetonitrile was added. The final mixture was centrifuged at 14,000 rpm for $5 \mathrm{~min}$. The supernatant was then transferred to an auto-injector vial and $10 \mu \mathrm{l}$ was injected into a Thermo ODS Hypersil C18 column (3 $\mu \mathrm{m}, 150 \times 4.6 \mathrm{~mm}$ ) (Thermo Scientific, Rockford, IL, USA). Isocratic separation was achieved using a mobile phase consisting of $150 \mathrm{mM} \mathrm{KH}_{2} \mathrm{PO}_{4}, 150 \mathrm{mM} \mathrm{KCl}(\mathrm{pH} \mathrm{6.0)}$, and $0.5 \%$ acetonitrile. The flow rate was set to $0.8 \mathrm{ml} / \mathrm{min}$ and a total run time of $20 \mathrm{~min}$. UV-HPLC analysis of ATP, ADP and AMP was performed using a Shimadzu SCL-10AVP system (Shimadzu Scientific Instruments, Columbia, MD, USA). Nucleotides were detected by their absorbance at $260 \mathrm{~nm}$ and compared with the elution position of standards. Retention times were 3.27, 4.68 and $4.87 \mathrm{~min}$ for ADP, AMP and ATP, respectively.

Cell cycle analysis by flow cytometry. Cells were harvested and fixed with $70 \%$ ethanol at $4^{\circ} \mathrm{C}$ for $24 \mathrm{~h}$. After removal of ethanol by washing with ice cold PBS, cells were resuspended in $1 \mathrm{ml}$ propidium iodide (PI) staining solution (4\% PI, $2 \mu \mathrm{g} / \mathrm{ml}$ RNase in PBS) and incubated for $30 \mathrm{~min}$ at $37^{\circ} \mathrm{C}$. Fluorescenceactivated cell sorting (FACS) analysis was performed using a CyAn ADP cytometer (Beckman Coulter, Inc.) as previously described (19).

Transient transfection with small interfering RNA (siRNA), To knockdown the endogenous AMPK, 3T3-L1 cells were transiently transfected with $100 \mathrm{nM}$ mouse siRNAs targeting AMPK $\alpha 1$ and AMPK $\alpha 2$ or with the non-silencing control siRNA using Lipofectamine ${ }^{\mathrm{TM}}$ RNAiMAX (Invitrogen) in culture medium without antibiotics according to the manufacturer's recommendations. After $24 \mathrm{~h}$, the medium was replaced with DM with or without $\mathrm{COH}-\mathrm{SR} 4$, and cell lysates were prepared $24 \mathrm{~h}$ or 7 days after drug treatment. In separate experiments, AMPK $\alpha 1 / \alpha 2$ siRNA-treated cells were incubated with or without COH-SR4 in DM for $48 \mathrm{~h}$ (day 0-2). The cells were then incubated in DM+ insulin for 2 days and normal DMEM/10\% FBS for 3 days. At day 7, differentiated cells were assayed for Oil Red $\mathrm{O}$ and AdipoRed staining. siRNA sequences used in the present study are available upon request.

Protein extraction and western blotting. 3T3-L1 cells were harvested and washed twice with ice cold PBS. Total cytosolic proteins were extracted with cell lysis buffer (Cell Signaling Technology), and the protein concentration was determined using the DC Protein Assay Kit (Bio-Rad, Hercules, CA, USA). Protein electrophoresis and western blotting were performed as described previously (19). Equal loading of proteins was confirmed by stripping and restaining the membranes with $\beta$-actin antibodies.

Statistical analyses. Statistical analyses were performed using Prism software (GraphPad, San Diego, CA, USA). Data are presented as means \pm SEM. Comparison of two groups was analyzed by the Student's t-test. For multiple group comparison, data were first analyzed by one-way ANOVA followed by Bonferonni's test. Values of $\mathrm{P}<0.05$ were considered to indicate statistically significant results.

\section{Results}

COH-SR4 activates AMPK. First, we investigated whether COH-SR4 activates AMPK in different types of cells. $\mathrm{COH}-\mathrm{SR} 4$ treatment resulted in a dose-dependent increase in the phosphorylation of AMPK and its substrate ACC in 3T3-L1 preadipocytes, as well as in cancer cells such as HL-60, HeLa, MCF-7 (Fig. 1B), A-549, H-358 and H-520 (data not shown), showing that this compound can activate AMPK in a wide variety of cells, similarly with AICAR, a known AMPK agonist. Pre-treatment with the AMPK inhibitor compound C blocked the ability of COH-SR4 to activate AMPK in 3T3-L1 cells, as indicated by the reduction in AMPK and 
A<smiles>O=C(Nc1cc(Cl)cc(Cl)c1)Nc1cc(Cl)cc(Cl)c1</smiles>
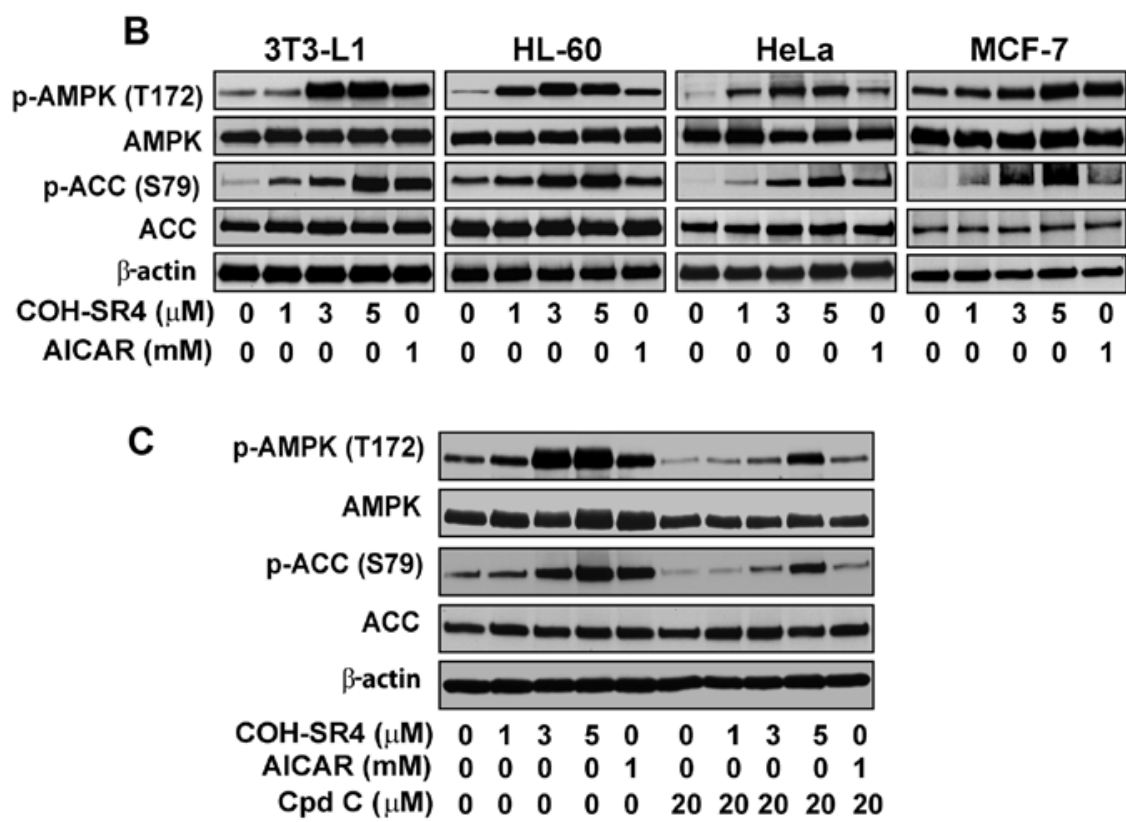

D

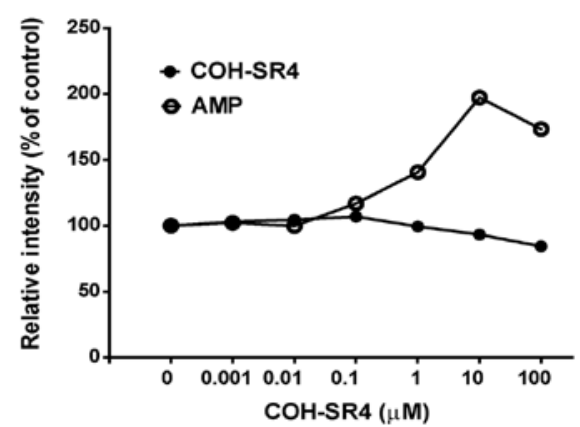

E

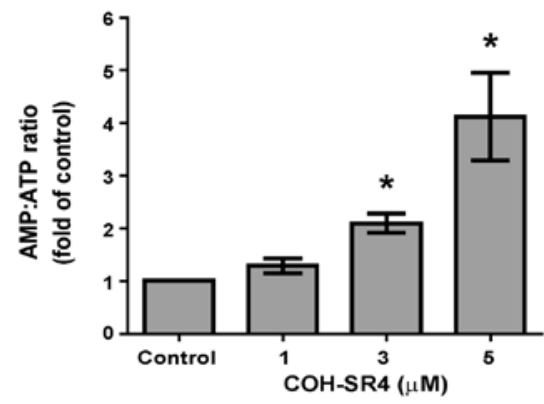

Figure 1. COH-SR4 indirectly activates AMPK. (A) Structure of COH-SR4, 1,3-bis(3,5-dichlorophenyl) urea. (B) Dose-dependent activation of AMPK in 3T3-L1 preadipocytes, HL-60, HeLa and MCF-7 cells. Cells were treated for $24 \mathrm{~h}$ with the indicated concentrations COH-SR4. Cell lysates were then analyzed by western blotting for phosphorylated and total AMPK, phosphorylated and total ACC, or $\beta$-actin levels. AICAR ( $1 \mathrm{mM})$ was used as a positive control for AMPK activation. (C) Effect of compound C treatment on AMPK activation by COH-SR4. 3T3-L1 cells were pre-treated for $1 \mathrm{~h}$ with compound C, followed by the addition of $\mathrm{COH}-\mathrm{SR} 4$ for $24 \mathrm{~h}$. Cell lysates were then analyzed by western blotting for phosphorylated and total AMPK, phosphorylated and total ACC or actin levels. (D) Effect of COH-SR4 on recombinant human AMPK activity. AMPK heterotrimer ( 1 1 $\beta 1 \gamma 1)$ activation was measured using the CycLex AMPK Kinase assay kit and is shown as the mean \pm SEM from three separate experiments. AMP was used as a positive control for AMPK activation. (E) Intracellular AMP:ATP ratios in 3T3-L1 preadipocytes cells following $1 \mathrm{~h}$ treatment with various concentrations of COH-SR4. Results are shown as means \pm SEM of three independent experiments with three replicates each $(\mathrm{n}=9)$. ${ }^{*} \mathrm{P}<0.05$.

ACC phosphorylation (Fig. 1C). In vitro assays with purified AMPK revealed that COH-SR4 is not a direct activator of the kinase (Fig. 1D), implying that this compound acts upstream from AMPK activation. Indeed, we observed that $\mathrm{COH}-\mathrm{SR} 4$ significantly decreased the intracellular ATP and increased the AMP:ATP ratio (Fig. 1E) in 3T3-L1 cells, further indicating that this compound indirectly activates AMPK.

COH-SR4 inhibits 3T3-L1 adipocyte differentiation. We next examined the effects of $\mathrm{COH}-\mathrm{SR} 4$ on adipocyte differentiation. 3T3-L1 preadipocytes were stimulated to differentiate in the presence of increasing concentrations of COH-SR4 (1-5 $\mu \mathrm{M})$. By day 7 of differentiation, COH-SR4 dose-dependently inhibited lipid accumulation as revealed by Oil Red $\mathrm{O}$ staining (Fig. 2A). In particular, treatment with either 3 or $5 \mu \mathrm{M}$ $\mathrm{COH}-\mathrm{SR} 4$ almost completely inhibited the formation of lipid droplets in the adipocytes and the cells appeared morphologically similar to the untreated preadipocyte control. The results of the Oil Red O staining were confirmed by quantitative analyses of intracellular triglyceride content. We estimated that $\mathrm{COH}-\mathrm{SR} 4$ inhibited lipid accumulation in 3T3-L1 adipocytes with an apparent $\mathrm{IC}_{50}$ of $\sim 1.5 \mu \mathrm{M}$ (Fig. 2B). These results demonstrated that $\mathrm{COH}-\mathrm{SR} 4$ is a potent inhibitor of adipocyte differentiation.

Adipogenesis is a highly regulated process requiring coordinated expression and activation of key transcription factors 
A

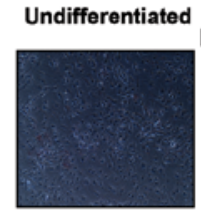

0 B

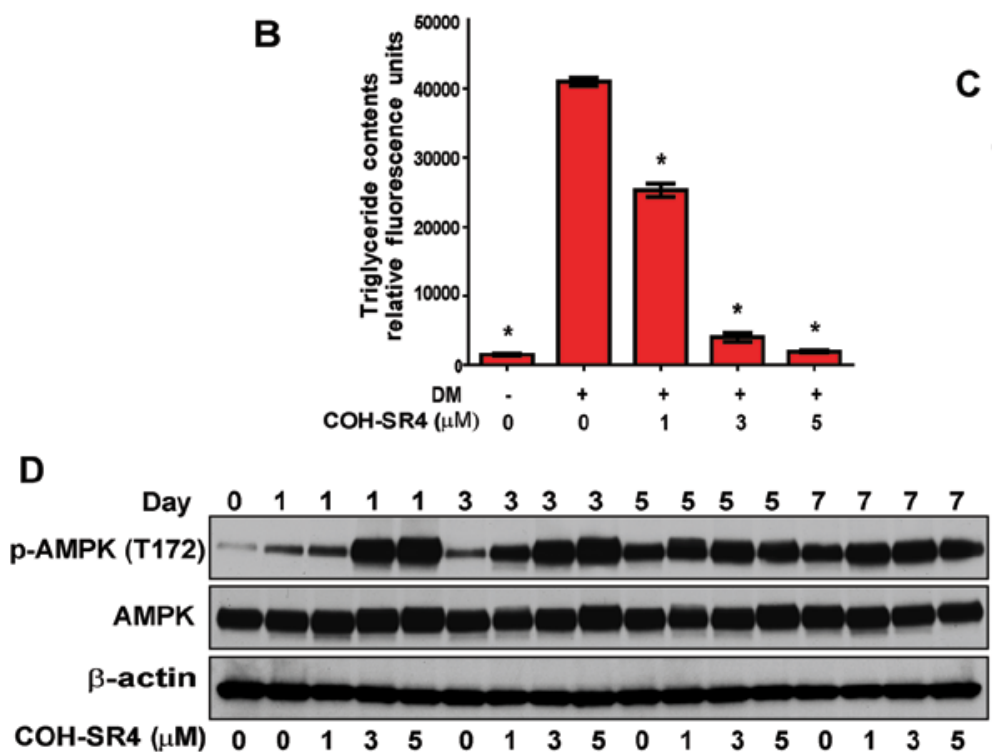

D

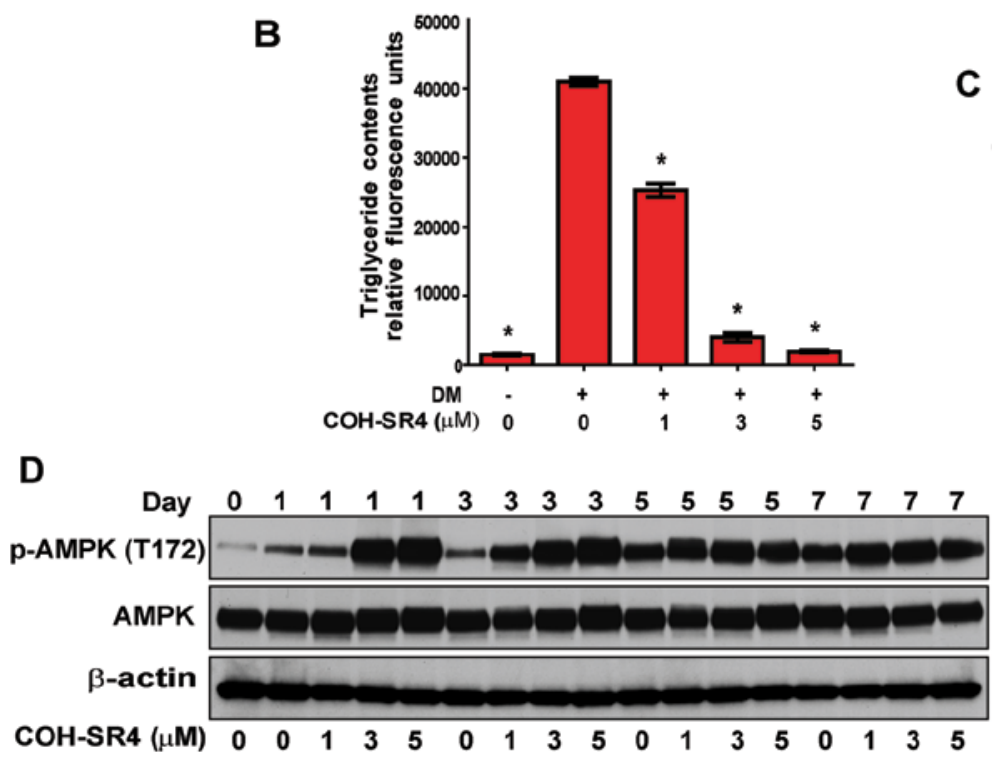

+ Differentiating media (DM)

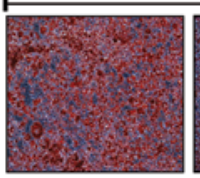

0

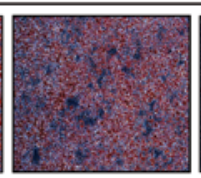

1

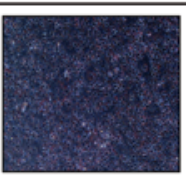

3

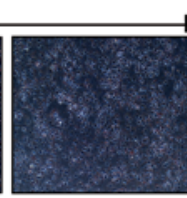

5

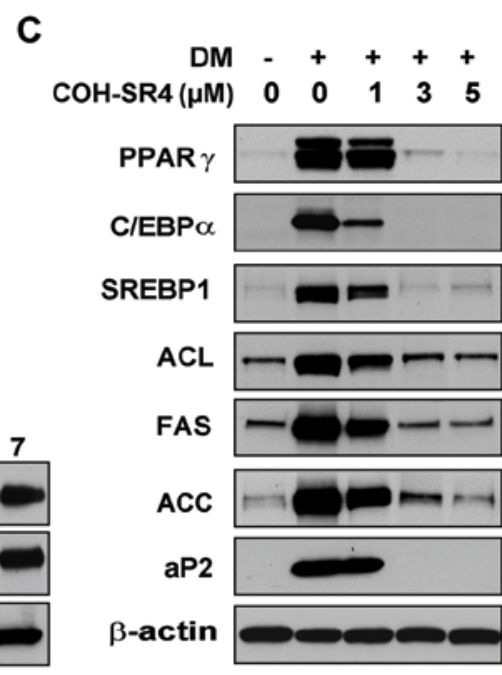

Figure 2. COH-SR4 inhibits adipocyte differentiation. Two-day post-confluent 3T3-L1 preadipocytes (day 0) were treated with the indicated concentrations of COH-SR4 or $0.02 \%$ DMSO (vehicle control) and were repleted every 2 days along with the relevant media cocktail until day 7 . (A) Intracellular lipids were stained with Oil Red O and visualized by phase-contrast microscopy (x100 magnification). (B) Intracellular triglyceride contents were measured with the AdipoRed kit. Results are shown as means \pm SEM of four independent experiments with two replicates each ( $\mathrm{n}=8)$; ${ }^{*} \mathrm{P}<0.05$. $(\mathrm{C}) \mathrm{Representative} \mathrm{western}$ blot analyses of 3T3-L1 cells treated with the indicated concentrations of COH-SR4 and then analyzed for key adipogenesis-related transcription factors and lipogenic proteins. After 7 days of differentiation, cells were lysed and equal amounts of solubilized protein were separated by SDS-PAGE, transferred to nitrocellulose, and immunoblotted with antibodies against PPAR $\gamma, \mathrm{C} / \mathrm{EBP} \alpha$, SREBP1, FAS, aP2, ACL and ACC. (D) Effects of COH-SR4 on the activation of AMPK $\alpha$ during 3T3-L1 differentiation. Protein extracts from the cells were collected at the indicated time points and analyzed by western blotting with phospho-AMPK, AMPK and $\beta$-actin antibodies.

which include C/EBPs, PPAR $\gamma$, SREBPs, as well as adipogenic genes such as FAS and aP2 $(6,9,10)$. Using western blotting, we confirmed the elevated expression of these adipogenic effectors when 3T3-L1 cells were allowed to differentiate for 7 days. Treatments with $\mathrm{COH}-\mathrm{SR} 4$ dose-dependently decreased the protein levels of PPAR $\gamma, \mathrm{C} / \mathrm{EBP} \alpha$, SREBP1, FAS and aP2, as well as ACL and ACC, key proteins involved in fatty acid synthesis (Fig. 2C). Taken together, these data indicate that $\mathrm{COH}-\mathrm{SR} 4$ effectively inhibited the expression of key adipogenesis-related proteins, thereby confirming its antiadipogenic properties.

Since we established that COH-SR4 activates AMPK in 3T3-L1 preadipocytes, we next investigated whether AMPK is activated by this compound during 3T3-L1 differentiation. Confluent 3T3-L1 preadipocytes were allowed to differentiate in the presence of various concentrations of $\mathrm{COH}-\mathrm{SR} 4$ for 7 days, and the proteins were analyzed by western blotting (Fig. 2D). Treatment with $\mathrm{COH}-\mathrm{SR} 4$ resulted in a time- and dose-dependent increase in phosphorylated AMPK. AMPK was activated as early as $1 \mathrm{~h}$ (data not shown) but the strongest activation mainly occurred during days 1 to 3 . Even though AMPK activation increased gradually during the differentiation in the absence of the test compound, COH-SR4 treatment rendered AMPK able to be in a fully activated state during the early differentiation phase, which was detrimental to adipocyte differentiation.

COH-SR4 inhibits MCE during the early stage of adipogenesis without inducing cytotoxicity and apoptosis. 3T3-L1 cells were treated at three different phases during the differentiation process: the proliferation phase (day 0-2), the differentiation phase (day 2-4) and the terminal differentiation phase (day 4-7). The effects of COH-SR4 on adipocyte differentiation were assessed on day 7 by Oil Red $\mathrm{O}$ staining. Treatment with $\mathrm{COH}-\mathrm{SR} 4$ during the proliferation phase (days 0-2) resulted in a nearly complete inhibition of lipid accumulation almost similar to that of a continuous (0-7 day) treatment, whereas the compound had lesser inhibitory effects when the cells were treated on days 2-4 only or 4-7 only (Fig. 3A). Moreover, the expression of adipogenic transcription factors and protein markers associated with adipogenesis were also suppressed when COH-SR4 treatment was carried out on days 0-2 of differentiation (Fig. 3B). These observations were almost similar to what was previously observed using day 0-7 treatment (Fig. 2C). Therefore, these data showed that the effects of $\mathrm{COH}-\mathrm{SR} 4$ that caused inhibition of adipocyte differentiation acted during the proliferation phase and were less effective at the later phases of differentiation. 
A

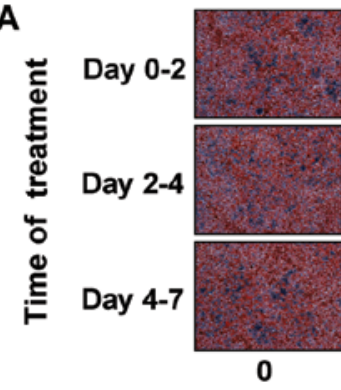

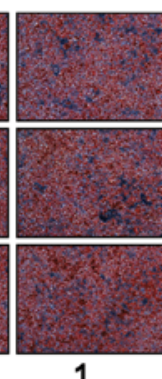

1

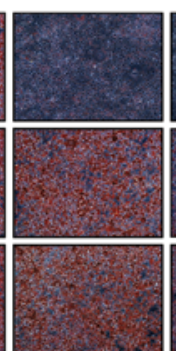

3

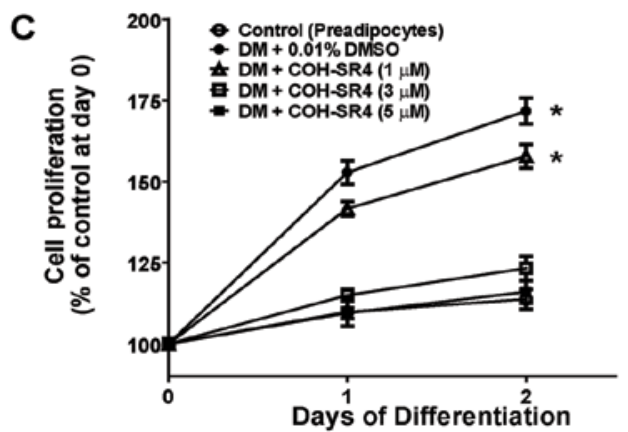

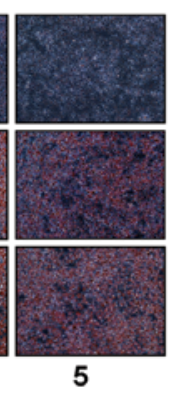

B

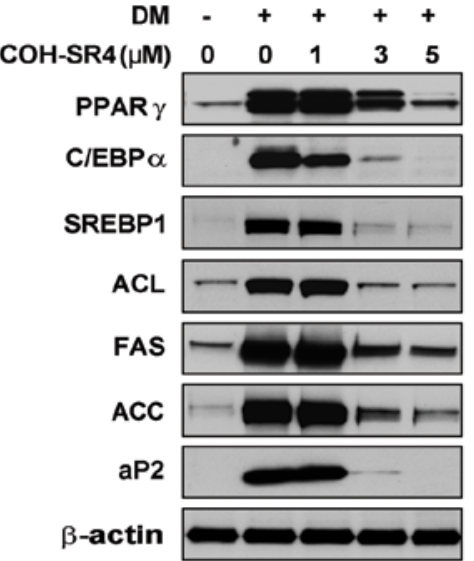

D

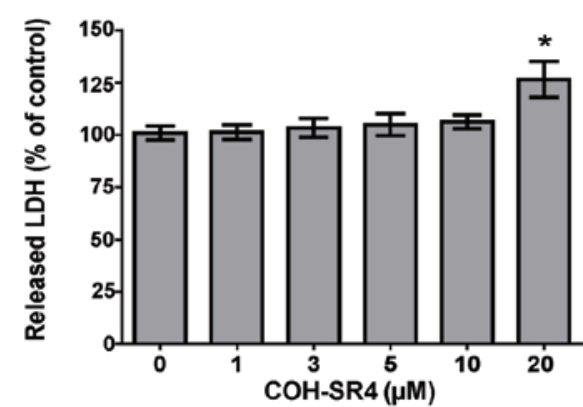

Figure 3. Effects of COH-SR4 on the different phases of adipocyte differentiation and on cell viability. (A) 3T3-L1 cells were treated with COH-SR4 or vehicle control during the different phases of adipocyte differentiation (days 0-2, 2-4 or 4-7). Cells were stained with Oil Red $\mathrm{O}$ on day 7 and visualized by phasecontrast microscopy (x100 magnification). (B) Western blots of key adipogenesis-related transcription factors (PPAR $\gamma$, SREBP1 and C/EBP $\alpha$ ) and marker proteins (FAS, aP2, ACL and ACC) from the protein extracts of 3T3-L1 cells treated with COH-SR4 on days 0-2 of differentiation. Proteins lysates were analyzed on day 7. Equal loading of proteins was assessed by $\beta$-actin staining. (C) Effects of COH-SR4 on adipocyte proliferation and cell viability. 3T3-L1 cells were treated with the indicated concentrations of $\mathrm{COH}$-SR4 during the proliferation phase (days 0-2). Undifferentiated 3T3-L1 cells on day 0 were used as the control. Cells were dissociated by trypsin treatment each day, and the total cell number was determined using a cell counter. (D) Cytotoxic effects of $\mathrm{COH}-\mathrm{SR} 4$ were assessed by measurement of released LDH in medium after $48 \mathrm{~h}$ of differentiation. (C and D) Results are shown as means \pm SEM of three independent experiments ( $\mathrm{n}=12$ and $\mathrm{n}=24$, respectively); ${ }^{*} \mathrm{P}<0.05$.

Since MCE is crucial for adipocyte differentiation, we next determined whether COH-SR4 affects preadipocyte MCE during the proliferation phase. 3T3-L1 cells were treated with increasing concentrations of COH-SR4 in DM cocktail medium and after 1-2 days, cell proliferation was estimated using a cell counter. While the number of DM-treated control cells increased $175 \%$ from day 0 to 2 , the number of 3T3-L1 cells treated with COH-SR4 decreased significantly in a dose-dependent fashion (Fig. 3C). However, the LDH cytotoxicity assay in proliferating preadipocytes revealed no noticeable toxicity associated with COH-SR4 at concentrations up to $20 \mu \mathrm{M}$ (Fig. 3D). In addition, $\mathrm{COH}-\mathrm{SR} 4$ did not induce apoptosis in these differentiating adipocytes (data not shown). These results demonstrated that COH-SR4 inhibited adipocyte differentiation at least partly via inhibition of MCE during the proliferation phase without interfering with cell viability or inducing apoptosis.

COH-SR4 promotes cell cycle arrest. $\mathrm{COH}-\mathrm{SR} 4$ treatment for $24 \mathrm{~h}$ of post-confluent 3T3 preadipocytes in DM cocktail led to a dose-dependent cell cycle arrest at the G1 phase (Fig. 4A, upper panel). The DNA content cytogram profile of $5 \mu \mathrm{M}$ of $\mathrm{COH}-\mathrm{SR} 4$ was comparable to that of the normal growth-arrested preadipocytes, suggesting that this compound inhibited clonal expansion of 3T3-L1 cells by inducing cell cycle arrest (Fig. 4A, lower panel). Western blot analysis of cell cycle regulator proteins confirmed that $\mathrm{COH}-\mathrm{SR} 4$ induces cell cycle arrest in differentiating 3T3-L1 cells. After a 24-h treatment, $\mathrm{COH}-\mathrm{SR} 4$ dose-dependently decreased the protein levels of cyclin A, cyclin B1 and CDK2, but not cyclin E1 (Fig. 4B). In addition, the protein level of p27, a potent CDK inhibitor involved in G1 arrest (21), was upregulated by $\mathrm{COH}-\mathrm{SR} 4$. Based on these results, $\mathrm{COH}-\mathrm{SR} 4$ treatment modulated the level of proteins active during $\mathrm{S}$ and $\mathrm{G} 2$ phases of the cell cycle, confirming the results of FACS analysis indicating G1 arrest induced by $\mathrm{COH}-\mathrm{SR} 4$.

COH-SR4 modulates mTORC1 but not mTORC2 function. To further elucidate the mechanism through which $\mathrm{COH}-\mathrm{SR} 4$ modulates the cell cycle and cell proliferation, we also analyzed proteins involved in mammalian target of rapamycin (mTOR) signaling, a multicomplex (mTORC1 and mTORC2) pathway that controls cell cycle progression and cell proliferation in many types of cells (22-25). Previous studies showed that AMPK inhibits mTOR by phosphorylating either tuberous sclerosis protein 2 (TSC2) or the mTORC1 subunit raptor directly $(26,27)$. Western blot analyses revealed that $\mathrm{COH}-\mathrm{SR} 4$ treatment dose-dependently increased the phosphorylation of both TCS2 and raptor (Fig. 4C). The increased phosphorylations coincided well with the robust phosphorylation and activation of AMPK. In addition, COH-SR4 decreased the phosphorylation of p70 $\mathrm{kDa}$ ribosomal protein S6 kinase (S6K) and eukaryotic initiation factor 4E (eIF4E) binding protein 
A

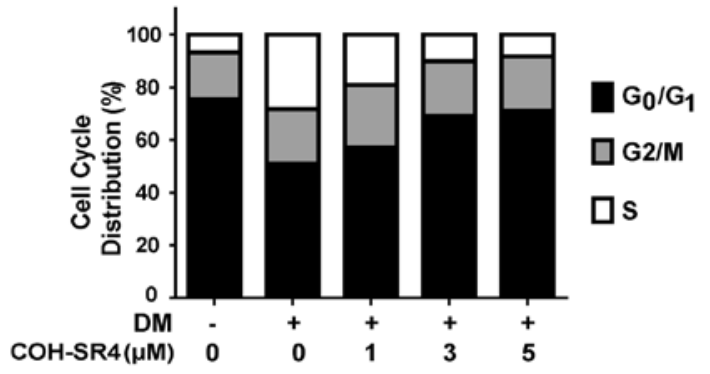

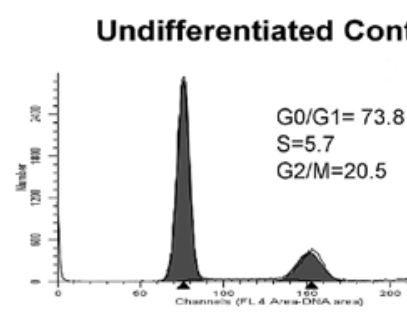

B

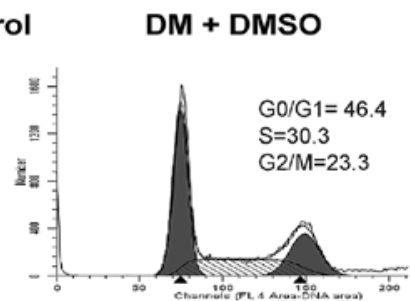

$\mathrm{DM}+5 \mathrm{uM}$ COH-SR4
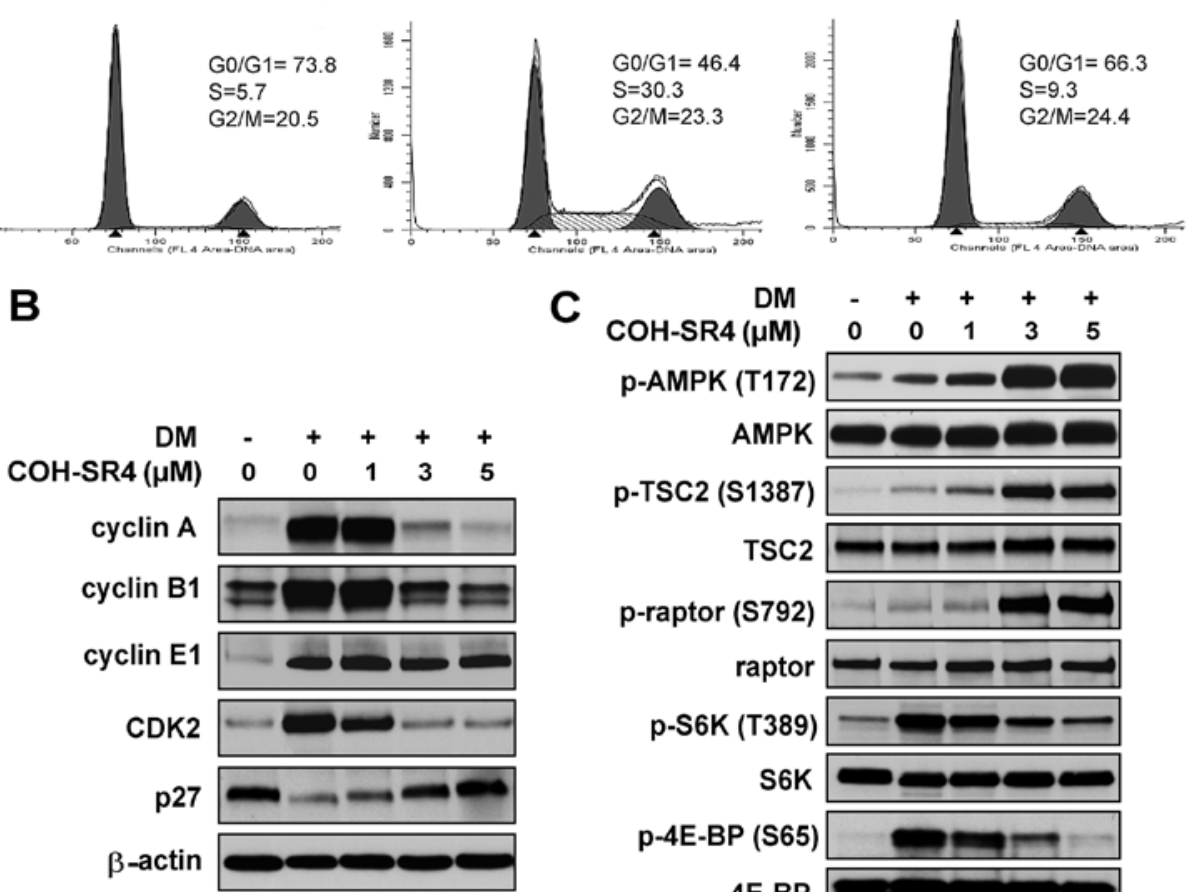

C

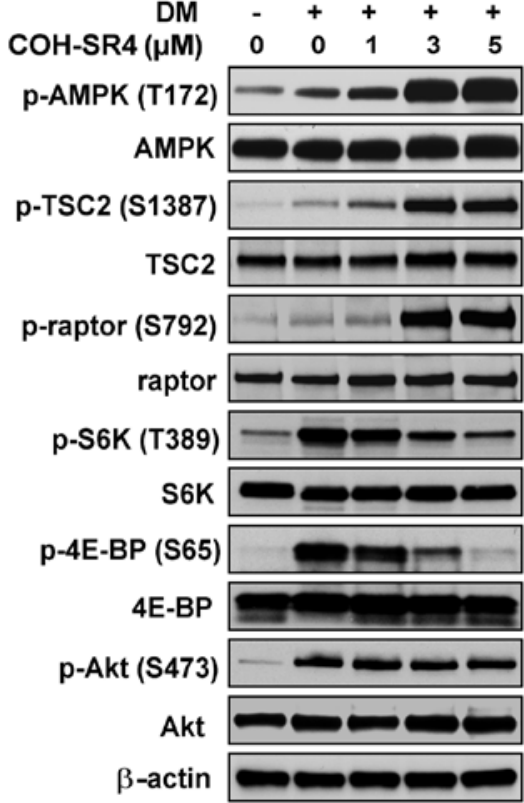

Figure 4. COH-SR4 causes cell cycle arrest and inhibits mTOR in differentiating adipocytes. (A) 3T3-L1 cells were exposed to DM with or without COH-SR4 for $24 \mathrm{~h}$. Cells were stained with PI solution followed by analyses of cell cycle distribution using flow cytometry. The percentage of the cell population at each stage of the cell cycle was determined using the ModFit software. Results were from three independent experiments with three replicates each (n=9). Representative western blot analyses showing the effects of COH-SR4 compound on (B) cell cycle regulatory proteins and (C) mTOR signaling. Total cell lysates from 3T3-L1 cells treated with DM with or without COH-SR4 for $24 \mathrm{~h}$ were resolved under electrophoresis and immunoblotted with antibodies against cyclin A, cyclin B1, cyclin E1, CDK2, p27 ${ }^{\mathrm{Kipl}}$, total and phosphorylated raptor, total and phosphorylated TSC2, total and phosphorylated p70SK6 (p-S6K), total and phosphorylated 4E-BP, total and phosphorylated Akt, and $\beta$-actin, which served as an internal control.

(4E-BP), two key downstream effectors of mTOR that regulate protein synthesis (22-25). Together, these results demonstrated that the activation of AMPK by $\mathrm{COH}-\mathrm{SR} 4$ and its subsequent inhibition of mTORC1 may be involved in the cell cycle arrest and inhibition of adipogenesis in 3T3-L1 cells.

We next examined whether COH-SR4 treatment modulates mTORC2. mTORC2 phosphorylates Akt on S473 (28). Therefore, to determine whether mTORC2 is also inhibited by $\mathrm{COH}-\mathrm{SR} 4$ under similar conditions, differentiating 3T3-L1 cells were treated with $\mathrm{COH}-\mathrm{SR} 4$, and the phosphorylation of Akt was determined. COH-SR4 treatment did not alter Akt phosphorylation (Fig. 4C). These results provide evidence that COH-SR4 only inhibits mTORC1 in differentiating adipocytes.
Knockdown of AMPK catalytic subunits by siRNA suppresses the inhibitory effects of $\mathrm{COH}-\mathrm{SR} 4$ on 3T3-L1 adipogenesis. To investigate whether COH-SR4-mediated AMPK activation is mainly responsible for inhibition of adipocyte differentiation, we employed siRNA interference that reduced the protein levels of AMPK catalytic subunits ( $\alpha 1$ and $\alpha 2)$ to $<20 \%$ of the control after $24 \mathrm{~h}$ (Fig. 5A). As expected, AMPK knockdown prevented the ability of $\mathrm{COH}-\mathrm{SR} 4$ to inhibit adipocyte development and lipid accumulation after 7 days as shown by Oil Red $\mathrm{O}$ staining and AdipoRed assay of intracellular triglycerides (Fig. 5B and C). Knockdown of AMPK $\alpha 1 / \alpha 2$ also suppressed the effects of $\mathrm{COH}-\mathrm{SR} 4$ on the expression of key adipogenic transcription factors and their target lipogenic genes. As shown by western blotting results, the increased 


\section{A}

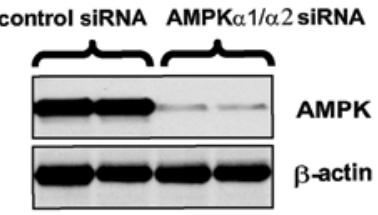

B

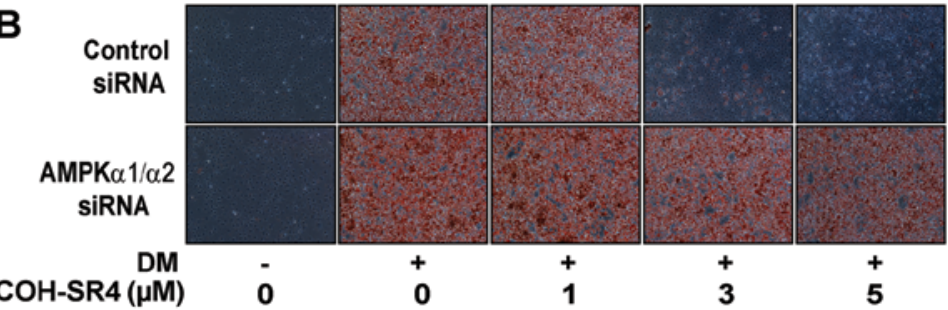

C

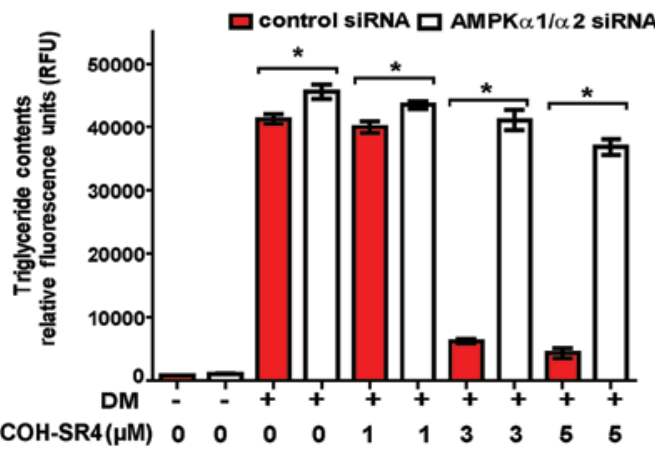

D

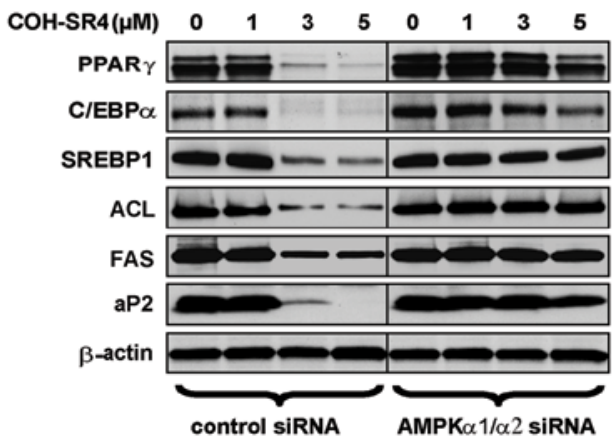

Figure 5. Effects of AMPKa1/ 22 siRNA knockdown and COH-SR4 treatment on adipocyte differentiaton. (A) Western blot analyses showing the efficiency of AMPK $\alpha 1 / \alpha 2$ knockdown in 3T3-L1 cells. (B) Oil Red O staining after 7 days of differentiation. 3T3-L1 preadipocytes were treated with AMPKa1/ 2 or control siRNA for $24 \mathrm{~h}$ followed by addition of DM cocktail in the absence/presence of COH-SR4 from day 0 to 2. Cells were then stained with Oil Red O on day 7, and cytoplasmic fats were observed under a phase contrast microscope (x100). (C) Intracellular triglyceride contents were measured with the AdipoRed reagent. Results are shown as means \pm SEM of four independent experiments; " $\mathrm{P}<0.05$. (D) Representative western blots of key adipogenesis-related transcription and adipogenic proteins from cells treated with control siRNA and AMPK $\alpha 1 / \alpha 2$ siRNA in the presence/absence of COH-SR4.

A Control siRNA + DM

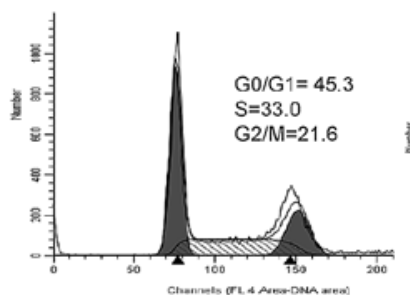

AMPK $\alpha 1 / \alpha 2$ siRNA + DM

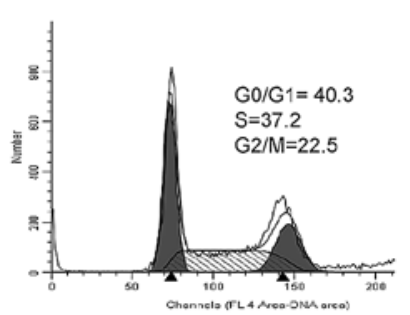

Control siRNA + DM $+5 \mu \mathrm{M}$ COH-SR4

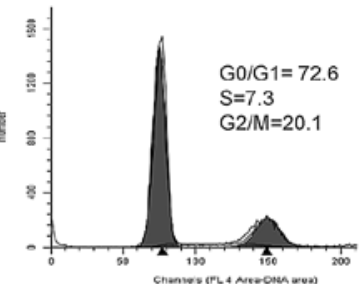

AMPK $\alpha 1 / \alpha 2$ SiRNA + DM $+5 \mu \mathrm{M}$ COH-SR4

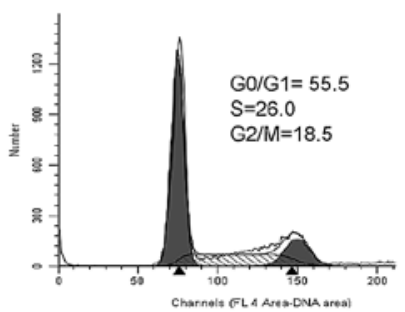

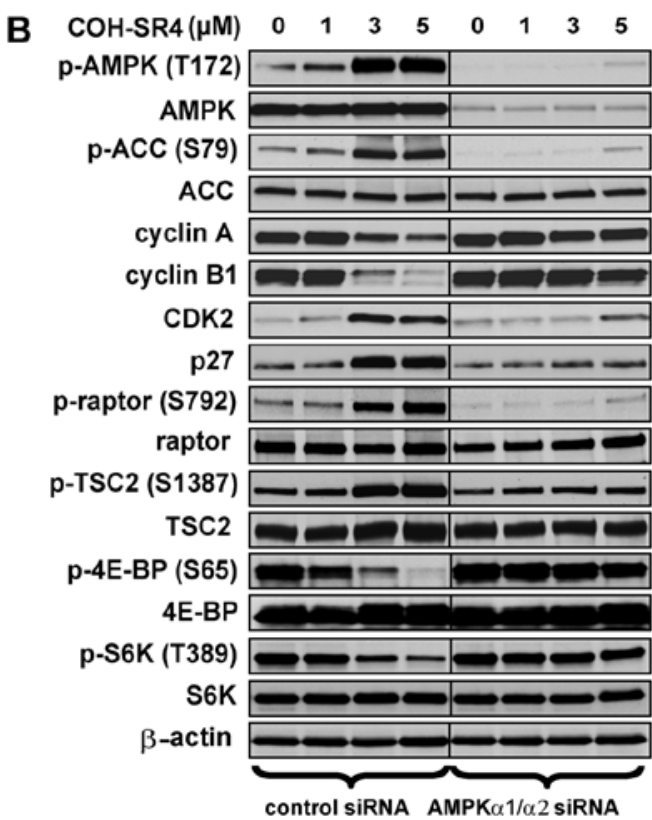

control siRNA AMPK $\alpha 1 / \alpha 2$ siRNA

Figure 6. Effects of AMPK $\alpha 1 / \alpha 2$ siRNA knockown and COH-SR4 treatment on the cell cycle and mTORC1 signaling pathway. 3T3-L1 preadipocytes were treated with AMPK $\alpha 1 / \alpha 2$ or control siRNA for $24 \mathrm{~h}$ followed by addition of DM cocktail in the absence/presence of COH-SR4. (A) After $24 \mathrm{~h}$, cells were stained with PI solution followed by analyses of cell cycle distribution using flow cytometry. The cell number in each cell cycle phase was calculated and expressed as overall percentage using ModFit software. (B) Representative western blots of cell cycle and mTORC1 signaling proteins.

protein levels of PPAR $\gamma, \mathrm{SREBP} 1, \mathrm{C} / \mathrm{EBP} \alpha, \mathrm{aP} 2, \mathrm{FAS}$ and ACL during adipocyte differentiation were all minimally affected by $\mathrm{COH}-\mathrm{SR} 4$ treatment, even at the highest concentration tested $(5 \mu \mathrm{M})$ (Fig. 5D).
Although the above findings clearly showed the involvement of AMPK activation in 3T3-L1 differentiation, we raised the question whether $\mathrm{COH}-\mathrm{SR} 4$ induces cell cycle arrest and the inhibition of mTORC1 requires AMPK. Silencing of AMPK $\alpha 1 /$ 
$\alpha 2$ also prevented $\mathrm{COH}-\mathrm{SR} 4$ to induce cell cycle arrest. In control siRNA-transfected cells, treatment of $5 \mu \mathrm{M}$ COH-SR4 arrested $\sim 70 \%$ of differentiating cells at the G1 phase (Fig. 6A) which was almost similar to non-transfected cells (Fig. 4A, lower panel). In AMPK $\alpha 1 / \alpha 2$ siRNA-transfected cells, COH-SR4 only arrested $\sim 55 \%$ of the cells at this stage and increased the number of $\mathrm{S}$ phase cells from 7 to $26 \%$ (Fig. 6A). Further support was provided by western blot analyses. Pre-treatment of AMPK $\alpha 1 / \alpha 2$ siRNA and COH-SR4 in differentiating 3T3-L1 cells had no or little noticeable effects on the protein levels of cyclin A, cyclin B1 and CDK2, while the amount of p27 protein remain unchanged (Fig. 6B). Additionally, AMPK $\alpha 1 /$ $\alpha 2$ knockdown abolished COH-SR4-mediated mTORC1 inhibition as the compound did not induce phosphorylation of both TSC2 and raptor, and failed to block the mTORC1-dependent phosphorylation of both S6K and 4EBP (Fig. 6B). Thus, these results further confirm that $\mathrm{COH}-\mathrm{SR} 4$ 's action on adipocyte differentiation is mainly due to its ability to indirectly activate the AMPK/mTORC1 signaling pathways and influence cell cycle progression and cell proliferation.

\section{Discussion}

AMPK, an energy-sensing enzyme involved in the regulation of carbohydrate and fat metabolism, has been suggested to play a role in the pathogenic development of obesity, type 2 diabetes and cancer, thus, making it an attractive drug target for the treatment of these metabolic diseases $(12,29)$. Our laboratory recently identified several novel small molecules with potential anticancer activities, including the lead compound COH-SR4, which exhibited strong anti-proliferative effects against leukemia and other types of human cancers in vitro and in vivo (19,20, unpublished data). Since an increase in de novo lipid synthesis is a hallmark of proliferating cancer cells (30), we investigated in the present study the potential of this compound to inhibit adipocyte differentiation and the underlying molecular mechanisms. Accordingly, we hypothesized that AMPK-mediated activation may be responsible for its anticancer and anti-adipogenic effects. The following new findings are reported in this study: i) COH-SR4 represents a new class of compounds that indirectly activates AMPK via increased AMP:ATP ratio; ii) $\mathrm{COH}-\mathrm{SR} 4$ prevents adipocyte differentiation by inducing cell cycle arrest and preventing MCE concurrent with AMPK activation during the proliferation phase; iii) $\mathrm{COH}-\mathrm{SR} 4$ inhibits the expression of key adipogenesis-related transcription factors and enzymes important in fatty acid and cholesterol synthesis; iv) $\mathrm{COH}-\mathrm{SR} 4$ stimulates AMPK phosphorylation and inhibits mTORC1 activity as evidenced by increased phosphorylation of raptor and TSC2, and reduced phosphorylation of S6K and 4EBP; and v) knockdown of AMPK $\alpha 1 / \alpha 2$ subunits suppresses the inhibitory effects of $\mathrm{COH}-\mathrm{SR} 4$ on adipogenesis, including cell cycle arrest, expression of adipogenesis-related transcription factors and proteins, as well as mTORC1 inhibition. Taken together, these results imply that $\mathrm{COH}-\mathrm{SR} 4$ inhibits adipocyte differentiation primarily by its effects on AMPK/mTORC1 signaling and associated downstream pathways related to cell growth, proliferation, and protein and lipid synthesis.

AMPK acts as a metabolic master switch regulating glucose and lipid metabolism $(10,11)$. At the cellular level, AMPK is activated by metabolic stressors that deplete ATP and activate AMP levels. Many of the well-known pharmacological drugs (biguanide derivatives, thiazolinediones, statins) as well as phytochemicals/nutraceuticals (berberine, resveratrol, genistein and capsaicin) with a wide variety of structures, are known to indirectly activate AMPK by inhibiting mitochondrial ATP production and altering the AMP:ATP ratios $(29,31)$. In this study, we showed that $\mathrm{COH}-\mathrm{SR} 4$ did not activate recombinant AMPK in vitro, suggesting that $\mathrm{COH}-\mathrm{SR} 4$ did not bind nor directly activate AMPK. Instead, COH-SR4 treatment resulted in increased intracellular AMP:ATP ratio, which suggests a potential effect on the mitochondria. A recent study showed that chemicals that can cause depolarization of mitochondrial membrane potential $(\Delta \psi \mathrm{m})$ can also activate AMPK (32). Interestingly, we previously found that $\mathrm{COH}-\mathrm{SR} 4$ decreased $\Delta \psi \mathrm{m}$ in HL-60 leukemia cells (19). We are currently investigating the effects of $\mathrm{COH}-\mathrm{SR} 4$ on the mitochondria to identify the exact molecular target of the compound.

Adipocyte differentiation is regulated by a transcriptional cascade that coordinates changes in the expression of specific adipocyte genes. Previous studies using agents to activate AMPK have linked this energy-sensing enzyme to the inhibition of adipogenesis. Both direct AMPK activators such as AICAR $(15,16)$ and A-76692 (17), as well as indirect activators such as resveratrol (33) and its analogs (18), and berberine (34) have been demonstrated to inhibit the expression of key lipogenic transcription factors and their target genes such as $\mathrm{C} /$ $\mathrm{EBP} \alpha, \mathrm{PPAR} \gamma, \mathrm{SREPB} 1, \mathrm{FAS}, \mathrm{aP} 2, \mathrm{ACC}$ and other proteins involved in fatty acid and cholesterol synthesis. In this study, we also observed a dose-dependent suppression of the protein levels of these various transcription factors and adipogenic genes by $\mathrm{COH}-\mathrm{SR} 4$ treatment, consequently leading to the prevention of the adipocyte phenotype as demonstrated by Oil Red $\mathrm{O}$ and AdipoRed stainings $\left(\mathrm{IC}_{50}\right.$ of $\left.\sim 2 \mu \mathrm{M}\right)$. Further analysis of the inhibitory effects of $\mathrm{COH}-\mathrm{SR} 4$ showed that the compound was more effective in blocking adipocyte differentiation during the proliferation phase (days 0-2), which was strongly associated with the early activation of AMPK during this period. Indeed, in 3T3-L1 cells where AMPK $\alpha 1 / \alpha 2$ were knocked down and then treated with $\mathrm{COH}-\mathrm{SR} 4$ during the proliferation phase, the compound failed to inhibit the expression of adipogenic transcription factors and proteins and suppress lipid droplet formation and triglyceride accumulation, confirming that activation of AMPK was primarily responsible for inhibition of differentiation. It has been speculated that this early activation of AMPK could be sensed by adipocytes as a signal of energy depletion, thus leading to inhibition of ATP-consuming pathways, such as lipogenesis (18).

Cell cycle analyses and cell proliferation assays supported the early effects of $\mathrm{COH}-\mathrm{SR} 4$ treatment on adipocyte differentiation. AMPK activation by $\mathrm{COH}-\mathrm{SR} 4$ during the proliferation phase induced cell cycle arrest and significantly suppressed preadipocyte MCE, the latter an important prerequisite for adipocyte differentiation. In particular, COH-SR4 blocked the cell cycle at the G1/S transition. Similarly, an AMPK activator, AICAR, has been recently reported to induce G1/S cell cycle arrest and inhibit proliferation in cancer cells (35). We also observed cell cycle arrest in human leukemia melanoma and lung and breast cancer cells (19,20, unpublished data). Overall, these data indicate that COH-SR4 induction of AMPK in both 
adipocytes and cancer cells results in cell cycle arrest, and thus, imply a common molecular target.

How AMPK modulates cell cycle progression, cell growth and proliferation in adipocytes is not totally clear, but accumulating evidence points to the AMPK/mTORC1 axis (23-25,36,37). Cell growth and proliferation are energetically demanding, and AMPK acts as an 'energy checkpoint' that permits growth and proliferation only when energy reserves are sufficient $(10,11,31)$. One of the key targets of AMPK is mTORC1, the master orchestrator of cell growth and proliferation. At the cellular level, mTORC1 promotes cellular anabolic processes, including ribosome biogenesis, protein and lipid synthesis, cell growth and cell cycle progression, which drive cell proliferation. Under energetic stress conditions, AMPK phosphorylates TSC2, and increases the activity of the TSC1-TSC2 complex to inhibit mTOR (27). In addition, AMPK also phosphorylates the mTORC1 component raptor leading to 14-3-3-binding and allosteric inhibition of mTORC1 (26). As shown in this study, COH-SR4 treatment dose-dependently increased the phosphorylation of both TSC2 and raptor, which correlated well with cell cycle arrest and prevention of MCE. Silencing of AMPK $\alpha 1 / \alpha 2$ subunits prevented the ability of $\mathrm{COH}-\mathrm{SR} 4$ to induce phosphorylation in both proteins, concomitant with the absence of cell cycle arrest and inhibition of lipid accumulation. Thus, COH-SR4 inhibits mTORC1 function indirectly via its AMPK activation effects. Consistent with our studies, the knockdown of raptor inhibited adipogenesis in 3T3-L1 cells (38), while loss of TSC2 enhanced 3T3-L1 differentiation (39). Moreover, we also observed increased phosphorylation of both TSC2 and raptor in growth-arrested human lung cancer cells treated with $\mathrm{COH}-\mathrm{SR} 4$ (unpublished data) further confirming the importance of mTORC1 signaling in cell cycle progression and proliferation, and again indicating a common downstream AMPK target by COH-SR4 in both cancer cells and adipocytes.

The mechanisms underlying mTORC1-mediated inhibition of cell growth and proliferation in adipocytes remain incompletely defined but likely involve reduced protein synthesis and induction of the translation of mRNA coding for key components of the adipogenic process. Activation of mTORC1 positively stimulates mRNA translation via its downstream substrates S6K and 4E-BPs/eIF4E $(22,25)$. Phosphorylation of 4E-BP by mTORC1 results in its dissociation from eIF4E, promoting assembly of the eIF4F complex and allowing eIF4E to initiate cap-dependent translation, while mTORC1-mediated phosphorylation of S6K1 promotes mRNA translation by phosphorylating and activating eIF4B; in turn, eIF4B enhances the activity of eIF4A, an RNA helicase that unwinds the structured 5 ' untranslated regions (5' UTRs) of many mRNAs $(23,24)$. 4E-BPs are crucial elements of the mTORC1 pathway that regulate cell number and proliferation by selectively inhibiting the translation of messenger RNAs that encode proliferation-promoting proteins and proteins involved in cell cycle progression (40). The activation of eIF4E, via inhibition of 4EBP activity, enhances cell proliferation by modulating the cell cycle through regulation of the expression of $\mathrm{G} 1 / \mathrm{S}$ proteins including cyclins A, B, D1 and E by promoting the export of specific mRNAs from the nucleus to the cytoplasm (41). Because eIF4E is thought to increase the translation of C/EBPs (42), which are key components required for the establishment of the adipogenic cascade, and that both $\mathrm{C} / \mathrm{EBP} \beta$ and $\mathrm{C} / \mathrm{EBP} \delta$ are known to drive the expression of $\mathrm{C} / \mathrm{EBP} \alpha$ and PPAR $\gamma$ to trigger the activation of a feed-forward loop in which these two transcription factors reciprocally induce their expression (43), we speculate that AMPK activation by COH-SR4 during the early proliferation phase of differentiation leads to inhibition of mTORC1-dependent translation of proteins and transcription factors associated with the adipogenic cascade. Thus, during adipocyte differentiation where the intracellular energy demands are higher as a consequence of increased protein biosynthetic rates that drive cell growth and MCE, the ability of $\mathrm{COH}-\mathrm{SR} 4$ to inhibit the high mTORC1 activity during this phase via AMPK activation would negatively affect the expression and activation of PPAR $\gamma$ and $\mathrm{C} / \mathrm{EBP} \alpha$. In support of this view, mTOR inhibition by rapamycin has been observed to induce G1/S cell cycle arrest, inhibit MCE, downregulate PPAR $\gamma, \mathrm{SREBP} 1$ and $\mathrm{C} / \mathrm{EBP} \alpha$ protein expression, as well as prevent lipid accumulation in differentiating 3T3 cells (44-47). Additionally, our present study showed that $\mathrm{COH}-\mathrm{SR} 4$ treatment inhibited both S6K and 4E-BP by decreasing their phosphorylation during adipocyte differentiation. Consequently, knockdown of AMPK $\alpha 1 / \alpha 2$ prevented dephosphorylation of both mTORC1 effectors, with noticeable absence of cell cycle arrest and inhibition of protein expression of key transcription factors and their target lipogenic genes. These findings are consistent with several studies where AMPK activators were shown to block S6K and 4E-BP phosphorylation $(48,49)$, and the failure of AMPK agonist AICAR to inhibit mTORC activity in AMPK $\alpha 1 / \alpha 2$ double knockout mice embryonic fibroblasts (50). Nonetheless, to better understand whether inhibition of adipocyte differentiation by $\mathrm{COH}-\mathrm{SR} 4$ is directly mediated through AMPK-mTORC1 signaling and cell cycle arrest, future investigations assessing the effects of the compound on raptor and/or TCS2-deficient, as well as p27-knockdown 3T3 cells are warranted.

In summary, we demonstrated that $\mathrm{COH}-\mathrm{SR} 4$ suppressed adipogenesis in 3T3-L1 cells through indirect activation of AMPK and downstream modulation of the mTORC1 signaling pathway, which blocked important regulators involved in protein synthesis, cell cycle progression, and expression of key transcription factors and their target adipogenic genes involved in lipid synthesis. In addition to exhibiting potent anticancer properties, $\mathrm{COH}-\mathrm{SR} 4$ is a potential therapeutic candidate for the treatment and prevention of obesity and related metabolic disorders. We are currently assessing the pharmacological effects of $\mathrm{COH}-\mathrm{SR} 4$ in diet-induced obese (DIO) mice as well as type 2 diabetic $\mathrm{db} / \mathrm{db}$ mice.

\section{Acknowledgements}

The authors are grateful to Mr. and Mrs. Isaac Moradi for their yearly financial support at the City of Hope. The authors are also thankful to Mariko Lee (Microscope Core Laboratory, $\mathrm{COH}$ ) and Lucy Brown (Analytical Cytometry Core Facility, $\mathrm{COH})$ for the technical assistance in the fluorescence microscopic and flow cytometric analyses, respectively. We also acknowledge the help of Dr Tim Synold and Lisa Powell (Analytical Pharmacology Laboratory) in the nucleotide measurements. 


\section{References}

1. Grundy SM: Obesity, metabolic syndrome, and cardiovascular disease. J Clin Endocrinol Metab 89: 2595-2600, 2004.

2. Khandekar MJ, Cohen P and Spiegelman BM: Molecular mechanisms of cancer development in obesity. Nat Rev Cancer 11: 886-895, 2011.

3. Jo J, Gavrilova O, Pack S, Jou W, Mullen S, Sumner AE, Cushman SW and Periwal V: Hypertrophy and/or hyperplasia: dynamics of adipose tissue growth. PLoS Comput Biol 5: e1000324, 2009

4. Pilch PF and Bergenhem N: Pharmacological targeting of adipocytes/fat metabolism for treatment of obesity and diabetes. Mo Pharmacol 70: 779-785, 2006.

5. Rosen ED and MacDougald OA: Adipocyte differentiation from the inside out. Nat Rev Mol Cell Biol 7: 885-896, 2006.

6. Lowe CE, O'Rahilly S and Rochford JJ: Adipogenesis at a glance. J Cell Sci 124: 2681-2686, 2011.

7. Tang QQ, Otto TC and Lane MD: Mitotic clonal expansion: a synchronous process required for adipogenesis. Proc Natl Acad Sci USA 100: 44-49, 2003.

8. Fajas L: Adipogenesis: a cross-talk between cell proliferation and cell differentiation. Ann Med 35: 79-85, 2003

9. Farmer SR: Transcriptional control of adipocyte formation. Cell Metab 4: 263-273, 2006.

10. Hardie DG: AMP-activated protein kinase: an energy sensor that regulates all aspects of cell function. Genes Dev 25: 1895-1908, 2011.

11. Carling D, Mayer FV,Sanders MJ and Gamblin SJ: AMP-activated protein kinase: nature's energy sensor. Nat Chem Biol 7: 512-518, 2011 .

12. Steinberg GR and Kemp BE: AMPK in health and disease. Physiol Rev 89: 1025-1078, 2009.

13. Villena JA, Viollet B, Andreelli F, Kahn A, Vaulont S and Sul HS Induced adiposity and adipocyte hypertrophy in mice lacking the AMP-activated protein kinase-alpha2 subunit. Diabetes 53 2242-2249, 2004

14. Zhang W, Zhang X, Wang H, et al: AMP-activated protein kinase $\alpha 1$ protects against diet-induced insulin resistance and obesity. Diabetes 61: 3114-3125, 2012.

15. Habinowski SA and Witters LA: The effects of AICAR on adipocyte differentiation of 3T3-L1 cells. Biochem Biophys Res Commun 286: 852-856, 2001.

16. Giri S, Rattan R, Haq E, Khan M, Yasmin R, Won JS, Key L Singh AK and Singh I: AICAR inhibits adipocyte differentiation in 3T3L1 and restores metabolic alterations in diet-induced obesity mice model. Nutr Metab 3: 31, 2006.

17. Zhou Y, Wang D, Zhu Q, Gao X, Yang S, Xu A and Wu D: Inhibitory effects of A-769662, a novel activator of AMP-activated protein kinase, on 3T3-L1 adipogenesis. Biol Pharm Bull 32: 993-998, 2009.

18. Vingtdeux V, Chandakkar P,Zhao H, Davies $P$ and Marambaud P Small-molecule activators of AMP-activated protein kinase (AMPK), RSVA314 and RSVA405, inhibit adipogenesis. Mol Med 17: 1022-1030, 2011.

19. Figarola JL, Weng Y, Lincoln C, Horne D and Rahbar S: Novel dichlorophenyl urea compounds inhibit proliferation of human leukemia HL-60 cells by inducing cell cycle arrest, differentiation and apoptosis. Invest New Drugs 30: 1413-1425, 2012.

20. Singhal SS, Figarola J, Singhal J, et al: 1,3-Bis(3,5-dichlorophenyl) urea compound 'COH-SR4' inhibits proliferation and activates apoptosis in melanoma. Biochem Pharmacol 84: 1419-1427, 2012.

21. Vermeulen K, Van Bockstaele DR and Berneman ZN: The cell cycle: a review of regulation, deregulation and therapeutic targets in cancer. Cell Prolif 36: 131-149, 2003.

22. Fingar DC, Richardson CJ, Tee AR, Cheatham L, Tsou C and Blenis J: mTOR controls cell cycle progression through its cell growth effectors S6K1 and 4E-BP1/eukaryotic translation initiation factor 4E. Mol Cell Biol 24: 200-216, 2004

23. Laplante $M$ and Sabatini DM: mTOR signaling in growth control and disease. Cell 149: 274-293, 2012.

24. Zoncu R, Efeyan A and Sabatini DM: mTOR: from growth signal integration to cancer, diabetes and ageing. Nat Rev Mol Cell Biol 12: 21-35, 2011.

25. Ma XM and Blenis J: Molecular mechanisms of mTOR-mediated translational control. Nat Rev Mol Cell Biol 10: 307-318, 2009.

26. Gwinn DM, Shackelford DB, Egan DF, Mihaylova MM, Mery A, Vasquez DS, Turk BE and Shaw RJ: AMPK phosphorylation of raptor mediates a metabolic checkpoint. Mol Cell 30: 214-226, 2008
27. Inoki $\mathrm{K}$, Zhu $\mathrm{T}$ and Guan KL: TSC2 mediates cellular energy response to control cell growth and survival. Cell 115: 577-590, 2003.

28. Sarbassov DD, Guertin DA, Ali SM and Sabatini DM Phosphorylation and regulation of $\mathrm{Akt} / \mathrm{PKB}$ by the rictor-mTOR complex. Science 307: 1098-1101, 2005.

29. Fogarty S and Hardie DG: Development of protein kinase activators: AMPK as a target in metabolic disorders and cancer. Biochim Biophys Acta 1804: 581-591, 2009.

30. Menendez JA and Lupu R: Fatty acid synthase and the lipogenic phenotype in cancer pathogenesis. Nat Rev Cancer 7: 763-777, 2007.

31. Hardie DG: Sensing of energy and nutrients by AMP-activated protein kinase. Am J Clin Nutr 93: 891S-896S, 2011.

32. Qiu BY, Turner N, Li YY, et al: High-throughput assay for modulators of mitochondrial membrane potential identifies a novel compound with beneficial effects on $\mathrm{db} / \mathrm{db}$ mice. Diabetes 59: 256-265, 2010

33. Chen S, Li Z, Li W, Shan Z and Zhu W: Resveratrol inhibits cell differentiation in 3T3-L1 adipocytes via activation of AMPK. Can J Physiol Pharmacol 89: 793-799, 2011.

34. Lee YS, Kim WS, Kim KH, et al: Berberine, a natural plant product, activates AMP-activated protein kinase with beneficial metabolic effects in diabetic and insulin-resistant states. Diabetes 55: 2256-2264, 2006.

35. Rattan R, Giri S, Singh AK and Singh I: 5-Aminoimidazole4-carboxamide-1-beta-D-ribofuranoside inhibits cancer cell proliferation in vitro and in vivo via AMP-activated protein kinase. J Biol Chem 280: 39582-39593, 2005.

36. Inoki K, Kim J and Guan KL: AMPK and mTOR in cellular energy homeostasis and drug targets. Annu Rev Pharmacol Toxicol 52: 381-400, 2012.

37. Laplante M and Sabatini DM: An emerging role of mTOR in lipid biosynthesis. Curr Biol 19: R1046-R1052, 2009.

38. Polak P, Cybulski N, Feige JN, Auwerx J, Rüegg MA and Hall MN: Adipose-specific knockout of raptor results in lean mice with enhanced mitochondrial respiration. Cell Metab 8: 399-410, 2008.

39. Zhang HH, Huang J, Düvel K, et al: Insulin stimulates adipogenesis through the Akt-TSC2-mTORC1 pathway. PLoS One 4: e6189, 2009.

40. Dowling RJ, Topisirovic I, Alain T, et al: mTORC1-mediated cell proliferation, but not cell growth, controlled by the 4E-BPs. Science 328: 1172-1176, 2010

41. Culjkovic B, Topisirovic I, Skrabanek L, Ruiz-Gutierrez M and Borden KL: eIF4E is a central node of an RNA regulon that governs cellular proliferation. J Cell Biol 175: 415-426, 2006.

42. Calkhoven CF, Muller C and Leutz A: Translational control of $\mathrm{C} / \mathrm{EBP}$ alpha and $\mathrm{C} / \mathrm{EBPbeta}$ isoform expression. Genes Dev 14: 1920-1932, 2000

43. Rosen ED, Hsu C-H, Wang X, Sakai S, Freeman MW, Gonzalez FJ and Spiegelman BM: C/EBPalpha induces adipogenesis through PPARgamma: a unified pathway. Genes Dev 16: 22-26, 2002.

44. Yeh WC, Bierer BE and McKnight SL: Rapamycin inhibits clonal expansion and adipogenic differentiation of 3T3-L1 cells. Proc Natl Acad Sci USA 92: 11086-11090, 1995.

45. Hashemolhosseini S, Nagamine Y, Morley SJ, Desrivières $S$, Mercep L and Ferrari S: Rapamycin inhibition of the G1 to S transition is mediated by effects on cyclin D1 mRNA and protein stability. J Biol Chem 273: 14424-14429, 1998.

46. Cho HJ, Park J, Lee HW, Lee YS and Kim JB: Regulation of adipocyte differentiation and insulin action with rapamycin. Biochem Biophys Res Commun 321: 942-948, 2004.

47. El-Chaar D, Gagnon A and Sorisky A: Inhibition of insulin signaling and adipogenesis by rapamycin: effect on phosphorylation of p70 S6 kinase vs eIF4E-BP1. Int J Obes Relat Metab Disord 28: 191-198, 2004

48. Kimura N, Tokunaga C, Dalal S, et al: A possible linkage between AMP-activated protein kinase (AMPK) and mammalian target of rapamycin (mTOR) signalling pathway. Genes Cells 8: 65-79, 2003.

49. Chiang PC, Lin SC, Pan SL, Kuo CH, et al: Antroquinonol displays anticancer potential against human hepatocellular carcinoma cells: a crucial role of AMPK and mTOR pathways. Biochem Pharmacol 79: 162-171, 2010.

50. Kalender A, Selvaraj A, Kim SY, et al: Metformin, independent of AMPK, inhibits MTORC1 in a rag GTPase-dependent manner. Cell Metab 11: 390-401, 2010. 